\title{
Author Correction: A novel atypical sperm centriole is functional during human fertilization
}

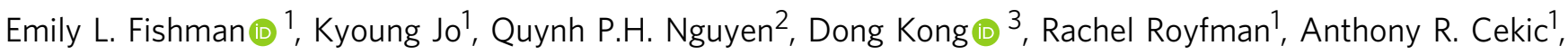 \\ Sushil Khanal ${ }^{1}$, Ann L. Miller (10 ${ }^{4}$, Calvin Simerly ${ }^{5}$, Gerald Schatten ${ }^{5}$, Jadranka Loncarek ${ }^{3}$, Vito Mennella ${ }^{2} \&$ \\ Tomer Avidor-Reiss ${ }^{1}$
}

Correction to: Nature Communications ; https://doi.org/10.1038/s41467-018-04678-8; published online 09 June 2018

In the original version of this Article, the affiliation details for Jadranka Loncarek and Vito Mennella were incorrectly given as 'Cell Biology Program, The Hospital for Sick Children, Department of Biochemistry, University of Toronto, 555 University Avenue, Toronto, ON, M5G 1X8, Canada' and 'Laboratory of Protein Dynamics and Signaling, Center for Cancer Research, National Cancer Institute, 1050 Boyles Street, Frederick, MD, 21702, USA', respectively. This has now been corrected in both the PDF and HTML versions of the Article.

Published online: 13 July 2018

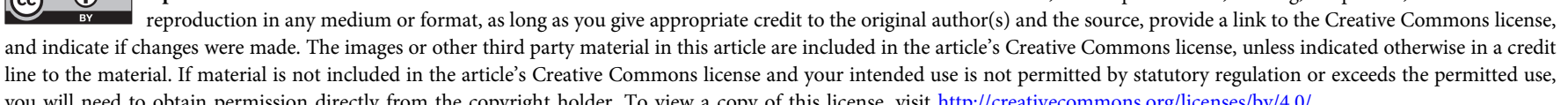
line to the material. If material is not included in the article's Creative Commons license and your intended use is not permitted by statutory regulation or
you will need to obtain permission directly from the copyright holder. To view a copy of this license, visit http://creativecommons.org/licenses/by/4.0/.

(c) The Author(s) 2018

\footnotetext{
${ }^{1}$ Department of Biological Sciences, University of Toledo, 2801W. Bancroft, Toledo, OH 43607, USA. ${ }^{2}$ Cell Biology Program, The Hospital for Sick Children, Department of Biochemistry, University of Toronto, 555 University Avenue, Toronto, ON M5G 1X8, Canada. ${ }^{3}$ Laboratory of Protein Dynamics and Signaling, Center for Cancer Research, National Cancer Institute, 1050 Boyles Street, Frederick, MD 21702, USA. ${ }^{4}$ Department of Molecular, Cellular, and Developmental Biology, University of Michigan, 830 North University Ave, Ann Arbor, MI 48109, USA. ${ }^{5}$ Departments of Cell Biology; Obstetrics, Gynecology and Reproductive Sciences; and Bioengineering, Magee-Womens Research Institute, University of Pittsburgh School of Medicine, 204 Craft Avenue, Pittsburgh, PA 15213, USA. Correspondence and requests for materials should be addressed to T.A-R. (email: Tomer.AvidorReiss@utoledo.edu)
} 